\title{
Antarctic Tourism Case Study
}

\author{
Jia Lei' ${ }^{1}$, Li Zhao², Ding Chen ${ }^{3}$ \\ ${ }^{1}$ School of Business, Southern Cross University, Gold Coast, Australia \\ ${ }^{2}$ Baoji Promotion Center for Industrial Development, Baoji, China \\ ${ }^{3}$ School of Economics and Management, Xi'an Shiyou University, Xi'an, China \\ Email: tintin.d.chen@gmail.com, 1165979304@qq.com
}

How to cite this paper: Lei, J., Zhao, L., \& Chen, D. (2020). Antarctic Tourism Case Study. Modern Economy, 11, 1497-1504. https://doi.org/10.4236/me.2020.118106

Received: July 8, 2020

Accepted: August 28, 2020

Published: August 31, 2020

Copyright ( 2020 by author(s) and Scientific Research Publishing Inc. This work is licensed under the Creative Commons Attribution International License (CC BY 4.0).

http://creativecommons.org/licenses/by/4.0/

\begin{abstract}
Antarctic is one of the popular international tourist destinations. This paper analyses the situation of Antarctic tourism by literature review. This paper argues that the number of Antarctic tourists is increasing, and its main attractions are wildlife, unique landscape and photography demand. The development of Antarctic tourism brings a key positive impact: makes tourists become the image ambassadors of Antarctic; a key negative impact: damages the ecological environment. Moreover, this paper believes that the two main development problems facing the development of Antarctic tourism are pollution control and management. The two main policy problems are: policy confusion and poor implementation.
\end{abstract}

\section{Keywords}

Antarctic Tourism, Antarctic Tourism Development, Wildlife, Ambassadors, Pollution

\section{Introduction}

With the development of science and technology, Antarctic tourism also got developed. The purpose of this paper is to analyze the Antarctic tourism issues. This paper studies the situation of tourist visitation to Antarctic with data analysis firstly. Next, the attraction of Antarctic tourism is analysed with relevant theories and articles. Furthermore, the positive and negative impacts of Antarctic tourism are explained. Fourthly, the two main problems of Antarctic tourism development are studied. Then, this paper analyses two main policy impacts of Antarctic tourism. Finally, a brief summary of this article is given.

\section{Visitor Analysis}

This part of this article will focus on the tourist analysis in recent years. The pre- 
vious studies show that the number of people traveling to Antarctic has increased gradually in recent years. A total of 36,702 people went to Antarctic in 2015 , and by 2018 , the total number of tourists had increased to 51,707 (IAATO, 2020). Further surveys show that the United States, China and Australia are the main sources of Antarctic tourist arrivals, accounting for 30\%, 16\% and $11 \%$ of the total number respectively in 2018. What's more, compared with the data a few years ago, the proportion of Chinese tourists to Antarctic tourists has risen the fastest. A few years ago, the proportion of Chinese tourists did not even reach $10 \%$ of total tourists (IAATO, 2020). Therefore, according to the basic data, this paper argues that the number of tourists to Antarctic is increasing gradually in recent years, and the growth rate of Chinese tourists is the fastest. Besides, international association of Antarctic tour operators also shows the types of tourists going to Antarctic in the past five years. From Figure 1, we can clearly see the number of different types of Antarctic tourists in the past five years. Non-landing tourism types account for the highest proportion, and the number of landing tourists accounts for the least. Among them, the number of non-landing tourists keeps increasing, while the number of non-landing tourists remains unchanged (IAATO, 2020).

\section{Main Attractive}

Most tourists have already identified their destinations before deciding to travel (Richards, 2002). More importantly, there are certain connections between tourist destinations and destination tourists, which help tourist destinations attract tourists (Botti, Peypoch, \& Solonandrasana, 2008). Tourist destinations use their own advantages to attract tourists, and tourists go to travel because of need, thus forming a closed-loop relationship with each other (Richards, 2002; Botti, Peypoch, \& Solonandrasana, 2008). About Antarctic tourism, there are three main purposes of why tourists want to visit Antarctic: wildlife, unique landscape and photographic needs.

typle of travel (2013-2018)

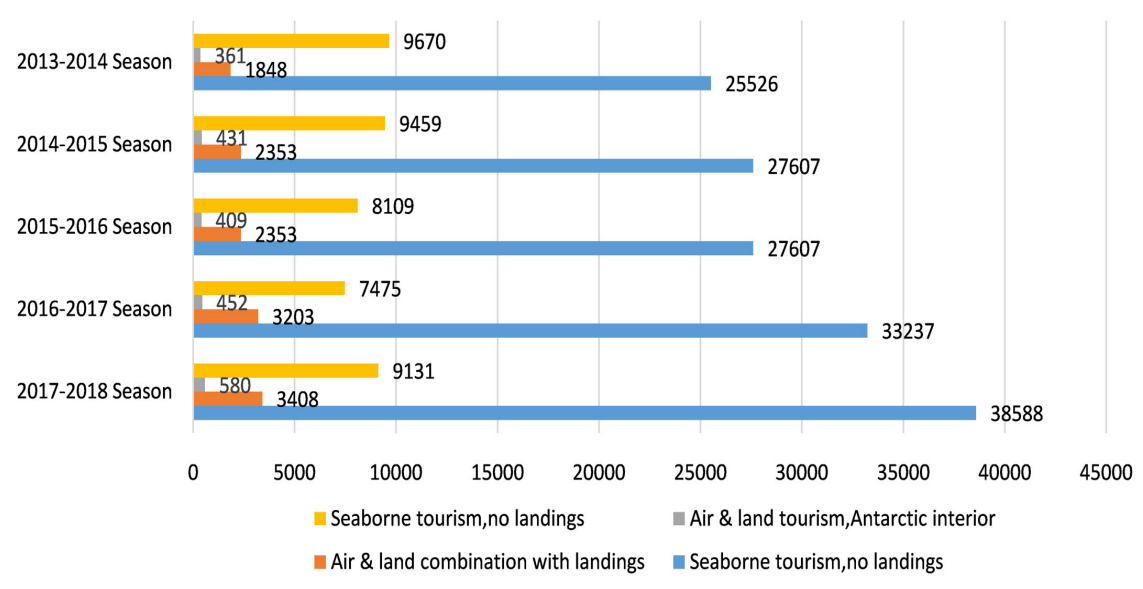

Figure 1. (IAATO, 2020). 
Firstly, Antarctic has a unique geographical location, different from other areas of the ecological environment, where also is the only habitat for many wildlife, the wildlife attracts the curiosity of tourists, and even some tourists to Antarctic just for having a look about the original habitat of Antarctic (One Step 4ward, 2020). In addition, there are many wild animals in Antarctic that we have never heard of before, such as whale seals, albatrosses, other seabirds and a series of invertebrates, which attract scholars and ecologists to visit (One Step 4ward, 2020; World Travel Guide, 2017).

Secondly, the most primitive eco-geographical environment in Antarctic has been preserved due to the extreme climate in Antarctic. This feature adds a sense of mystery to Antarctic and attracts the attention of explorers and natural landscape enthusiasts (Bauer, 2013).

Thirdly, due to the special environment and geographical location of Antarctic, Antarctic has a unique landscape, attracting photographers to travel. Moreover, different cliffs in Antarctic are covered with ice and snow, creating a wonderful scene, which is also a great attraction for people to travel to the Antarctic (Bauer, 2013).

Therefore, the motivation of tourists to Antarctic is formed by their different needs for Antarctic, and the reason why Antarctic can attract tourists is because of its unique conditions.

\section{Tourism Activity Impact}

With the development of Antarctic tourism, it will inevitably bring some influence. This part mainly studies one of the most important positive and one of the most important negative impacts of Antarctic tourism development. This article holds that the main positive impact of Antarctic tourism is that tourists have become the image ambassadors of Antarctic. The main negative impact is the destruction of the ecological environment.

\subsection{Negative Impact}

With the number of Antarctic tourists increasing, the ecological environment of Antarctic will inevitably be affected. The negative impact of Antarctic tourism development on the ecological environment is mainly manifested in the following aspects. Firstly, the microbes that people travel to Antarctic will be left unconsciously in Antarctic, and "seeds, bryophytes and lichen fragments are inadvertently introduced into Antarctic", increasing the biodiversity of Antarctic and destroying the original ecological balance (Huiskes et al., 2014). Secondly, people's tourism activities in Antarctic have a certain impact on the life of Antarctic organisms. To a certain extent, they occupy the habitats of some animals, especially the habitats and reproductive activities of birds, which have been greatly affected. And people's garbage also pollutes the environment and affects the balance of the ecological environment (Liggett et al., 2011; Huiskes et al., 2014). Thirdly, with the increasing number of tourists, the demand for trans- 
portation to Antarctic has also increased. The frequency of air and ship transport does not match the demand for tail gas treatment, which could lead to climate warming and break the ecological balance (Liggett et al., 2011; Huiskes et al., 2014). Fourthly, the development of tourism also increases the demand for infrastructure construction in Antarctic, which will pollute the Antarctic environment and require regular maintenance of infrastructure (Liggett et al., 2011). In this process, it also will pollute the Antarctic environment, and because of the increase of tourism demand, this pollution will be sustainable and destroy life.

\subsection{Positive Impact}

On the other hand, although Antarctic tourism has caused some damage to the ecological environment, there are still have positive impacts on Antarctic travel. Most tourists to Antarctic have become potential ambassadors to publicize Antarctic. According to Powell, Kellert and Ham's research results, Antarctic tourism has increased tourists' awareness of Antarctic, improved tourists' behaviour, enhanced tourists' awareness of environmental protection and charity, and increased tourists' knowledge (2008). Firstly, after a trip to Antarctic, most tourists spontaneously become ambassadors of Antarctic tourism image, consciously calling on people to protect Antarctic wildlife and ecological environment. Most tourists pay more attention to saving resources and protecting the environment in their daily life after they return home from Antarctic tourism. In addition, tourists' awareness of environmental protection has been improved. More importantly, tourists have responded more actively to the donation activities of Antarctic tourism development, and at the same time, they have responded positively to the charitable activities related to environmental protection and strongly supported them (Powell, Kellert, \& Ham, 2008).

\section{Two Key Issues of the Antarctic Tourism Development}

Nowadays, Antarctic tourism has been accepted widely, but the development of Antarctic tourism is also facing some problems. Based on the literature analysis, this paper considers that the pollution and management problems are the two main problems that need to be solved in Antarctic tourism development at present and future.

Combined with the main negative impacts of Antarctic tourism. It is obvious shows that the development of Antarctic tourism will cause some pollution issues to the environment. Specifically, Antarctic tourism development will inevitably increase the number of tourists to Antarctic, so the number and species of microorganisms that people unconsciously bring into Antarctic have been increased, which aggravates the ecological environmental pollution in Antarctic (Huiskes et al., 2014). Secondly, the development of Antarctic tourism is accompanied by the demand for Antarctic infrastructure, which reduces the proportion of the ice-free surface of Antarctic, and the construction of infrastructure occupies the original place (Kariminia, Sabarinah, Hashim, \& Ismai, 2019; 
Huiskes et al., 2014). Thirdly, the development of science and technology has accelerated the development of Antarctic tourism, but the related pollution treatment technology does not meet the needs of people for the development of Antarctic tourism (Kariminia, Sabarinah, Hashim, \& Ismai, 2019). Fourthly, combined with the analysis of the attractiveness of Antarctic tourism in this paper, the inability to solve the problem of Antarctic pollution will certainly have some impact on Antarctic wildlife and natural landscape, and will weaken the attraction of Antarctic to tourists (Antarctic Tourism-Human Impacts Threats to the Environment, 2017). Fifthly, both infrastructure construction and tourist activities in Antarctic need transportation to complete. Current science and technology are insufficient to deal with the exhaust pollution caused by aircraft and ships. This pollution cannot be solved. It is difficult to increase investment in transportation, which will eventually hinder the development of Antarctic tourism (Antarctic Tourism-Human Impacts Threats to the Environment, 2017; Australian Government, 2012). Moreover, the prosperity of Antarctic tourism is bound to be accompanied by environmental pollution. Today, the world's ecological environment has been destroyed. If the pollution problem cannot be solved well, there will be no balance between the development of Antarctic tourism at the expense of the environment or the improvement of the environment at the expense of Antarctic tourism (Australian Government, 2012). Therefore, combined with previous studies, it is inevitable that Antarctic tourism will hinder the development of Antarctic tourism if the environmental pollution problems caused by Antarctic tourism cannot be solved.

On the other hand, according to Student, Amelung, and Lamers's (2016) study, another big problem of Antarctic tourism development is the management of Antarctic tourism. The obstacles of management problems to Antarctic tourism development are mainly reflected in the following aspects. Firstly, Student, Amelung, and Lamers (2016) believe that the development of Antarctic tourism needs a comprehensive and binding tourism framework to manage Antarctic tourism and regulate tourists' activities in Antarctic and the extent of Antarctic opening to the outside world. Secondly, the development of Antarctic tourism has resulted in the diversification of Antarctic tourism operators. If the operators are not managed in a unified way, Antarctic tourism will be chaotic, disturbing the market environment of Antarctic tourism and destroying the environment of Antarctic tourism (Student, Amelung, \& Lamers, 2016; Verbitsky, 2013). Thirdly, the operators of Antarctic tourism are multi-faceted. If the management of Antarctic tourism is not solved, the operators' differences in dealing with Antarctic tourism will be resolved through disputes, which could reduce the efficiency of solving the problem and delay the development of Antarctic tourism (Verbitsky, 2013). Fourthly, because of the diversification of operation, the cost of Antarctic tourism is reduced, but at the same time, it also increases the difficulty of controlling Antarctic tourism. Without a good management system, the commitment of operators is difficult to be controlled, and the degree 
of their behavior norms is greatly weakened, which could lead to the aggravation of Antarctic pollution (Student, Amelung, \& Lamers, 2016; Verbitsky, 2013). Finally, the implementation of Antarctic tourism policies needs to be monitored. The lack of a sound management system could reduce the intensity of the implementation of Antarctic tourism policies, lead to internal management chaos, uncontrollable Antarctic tourism, and hinder the pace of Antarctic tourism development (Verbitsky, 2013).

In short, management and pollution are two major obstacles to the development of Antarctic tourism. Management plays an important role in promoting the development of Antarctic tourism. Establishing a management system is a significant prerequisite for the development of Antarctic tourism. Pollution has greatly hindered the development of Antarctic tourism. Solving pollution is a necessary condition for the development of Antarctic tourism.

\section{Two Policy Implications}

While focusing on solving pollution control and management problems, the policy issues of Antarctic tourism development should not be ignored. Through analysing the previous studies, this paper considers that the main policy problems facing Antarctic tourism development are: policy confusion and weak policy implementation. According to Lamers, Liggett, \& Amelung (2012), the issue that Antarctic tourism development policies are formulated and implemented by relying on joint management with multiple organizations has become a major problem. Specifically, it means that the relevant policies on Antarctic tourism development have been in an unorganized chaotic state without systematic supervision (Lamers, Liggett, \& Amelung, 2012). The specific concept of Antarctic tourism development policy is vague, and there is no unified opinion to formulate and manage the policy. Because Antarctic does not belong to any country, the management of Antarctic is anarchic, resulting in the lack of review of relevant tourism policies (Lamers, Liggett, \& Amelung, 2012). Most of the relevant organizations formulate Antarctic tourism development policies based on their own interests, so that Antarctic tourism development policies are confused (Lamers, Liggett, \& Amelung, 2012). At the same time, due to the management of Antarctic NGOs, the implementation of relevant policies is weak. According to Li's (2013) study, the implementation of Antarctic tourism-related policies mainly depends on the implementation of operators, lack of supervision, so the implementation of policies lacks security, high uncertainty, resulting in the implementation of Antarctic tourism development policy is weak (Li, 2013).

On the other hand, according to Li (2013) research results, the chaos of Antarctic tourism development policy will have a negative impact on Antarctic tourism development, mainly in the following aspects. Firstly, it will cause many organizations to doubt the validity of the Antarctic Tourism Agreement, or even to violate the Agreement, which is not conducive to the protection of the Antarctic ecological environment (Li, 2013). Secondly, policy confusion will cause 
people to confuse the truth of relevant policies, which is not conducive to the implementation of favorable policies (Lamers, Liggett, \& Amelung, 2012; Li, 2013). Thirdly, policy chaos could lead to management chaos and waste of resources. Weak policy implementation also has a negative impact on Antarctic tourism development (Li, 2013). Furthermore, the lack of effective implementation of relevant policies will lead to a reduction in the supervision of Antarctic tourism, which is not conducive to information feedback. And, the failure to implement favorable policies could delay the best time to solve relevant problems, which is not conducive to the development of Antarctic tourism. Moreover, weak policy implementation will reduce managers' attention to policy formulation and implementation feedback, and even cause confusion in Antarctic tourism regulation (Lamers, Liggett, \& Amelung, 2012; Li, 2013).

Conclusion, both policy chaos and low policy implementation level could slow down the development of Antarctic tourism.

\section{Conclusion}

Combined with the data analysis of the number of tourists in recent years, this paper believes that Antarctic tourism is in a period of rapid development. With the development of science and technology, people are more and more curious about world. The unique natural scenery, wild animals and natural photography natural landscape in Antarctica attract people to travel to Antarctica more and more. However, with the rapid development of Antarctic tourism, due to the increase of human activities in Antarctica, the natural ecological balance of Antarctica is also gradually destroyed. Human activities have brought pollution sources to Antarctica. In addition, due to the unique geographical location of Antarctica, there are political disputes and low implementation rate of governance measures in the management of Antarctica, which reduces the ability of Antarctic pollution control. Although the data analysis and literature review of this paper are not comprehensive, this paper believes that solving the current management problems of Antarctica, focus on pollution prevention and protection of ecological balance are the preconditions for the development of Antarctica.

\section{Conflicts of Interest}

The authors declare no conflicts of interest regarding the publication of this paper.

\section{References}

Antarctic Tourism-Human Impacts Threats to the Environment (2017). https://www.coolAntarctic.com/Antarctic\%20fact\%20file/science/threats_tourism.php

Australian Government (2012). Human Impact on Antarctica. https://www.antarctica.gov.au/about-antarctica/environment/human-impacts-in-antar ctical

Bauer, T. G. (2013). Tourism in the Antarctic: Opportunities, Constraints, and Future 
Prospects. New York: Haworth Hospitality Press. https://doi.org/10.4324/9780203048214

Botti, L., Peypoch, N., \& Solonandrasana, B. (2008). Time and Tourism Attraction. Tourism Management, 29, 594-596. https://doi.org/10.1016/j.tourman.2007.02.011

Huiskes, A., Gremmen, N. J. M., Bergstrom, D. M., Frenot, Y., Hughes, K. A., Imura, S., Kiefer, K., Lebouvier, M., Lee, J. E., Tsujimoto, M., Ware, C., Vijver, V. D. B., \& Chown, S. L. (2014). Aliens in Antarctic: Assessing Transfer of Plant Propagules by Human Visitors to Reduce Invasion Risk. Biological Conservation, 171, 278-284. https://doi.org/10.1016/j.biocon.2014.01.038

IAATO (2020). Data \& Statistics. https://iaato.org/information-resources/data-statistics/

Kariminia, S., Sabarinah, S. A., Hashim, R., \& Ismail, Z. (2019). Environmental Consequences of Antarctic Tourism from a Global Perspective. Procedia-Social and Behavioral Sciences, 105, 781-791. https://www.sciencedirect.com/science/article/pii/S187704281304456X

Lamers, M., Liggett, D., \& Amelung, B. (2012). Strategic Challenges of Tourism Development and Governance in Antarctic: Taking Stock and Moving forward. Polar Research, 31, Article No. 17219. https://doi.org/10.3402/polar.v31i0.17219

Li, S. (2013). Antarctic Tourism: The Urgent Need for a New Comprehensive Regulatory Regime. New Zealand Journal of Environmental Law, 17, 321-334.

Liggett, D., Mcintosh, A., Thompson, A., Gilbert, N., \& Storey, B. (2011). From Frozen Continent to Tourism Hotspot? Five Decades of Antarctic Tourism Development and Management, and a Glimpse into the Future. Tourism Management, 32, 357-366. https://doi.org/10.1016/j.tourman.2010.03.005

One Step 4ward (2020). 5 Reasons to go to Antarctic. https://onestep4ward.com/five-reasons-to-visit-antarctica/

Powell, R., Kellert, S., \& Ham, S. (2008). Antarctic Tourists: Ambassadors or Consumers? The Polar Record, 44, 233-241. https://doi.org/10.1017/S0032247408007456

Richards, G. (2002). Tourism Attraction Systems: Exploring Cultural Behavior. Annals of Tourism Research, 29, 1048-1064. https://doi.org/10.1016/S0160-7383(02)00026-9

Student, J., Amelung, B., \& Lamers, M. (2016). Towards a Tipping Point? Exploring the Capacity to Self-Regulate Antarctic Tourism Using Agent-Based Modelling. Journal of Sustainable Tourism, 24, 412-429. https://doi.org/10.1080/09669582.2015.1107079

Verbitsky, J. (2013). Antarctic Tourism Management and Regulation: The Need for Change. The Polar Record, 49, 278-285. https://doi.org/10.1017/S003224741200071X

World Travel Guide (2017). Things to See and Do in Antarctic. https://www.worldtravelguide.net/guides/Antarctic/Antarctic/things-to-do 